\title{
Detailed analysis of a new translocation in pig
}

\author{
NM Astachova *, LV Vysotskaya, AS Graphodatsky \\ Institute of Cytology and Genetics, Academy of Sciences of the USSR, \\ Siberian Division, Novosibirsk-90, USSR
}

(Proceedings of the 9th European Colloquium on Cytogenetics of Domestic Animals; Toulouse-Auzeville, 10-13 July 1990)

reciprocal translocation / swine

\section{INTRODUCTION}

Today the necessity of cytogenetic control methods in farm animal breeding has become evident. Using animals with chromosome aberrations causes economic losses, much greater than those spent on chromosome analysis (Fechheimer, 1979; Gustavsson, 1980; Popescu and Tixier, 1984). Reciprocal translocations are the most widespread chromosome aberrations in domestic pigs.

\section{MATERIALS AND METHODS}

The laboratory pigs, obtained by reproductive interbreeding of Swedish Landrace, Vietnamese Black swine, Central Asian and Central European wild boars, were bred at the experimental farm in the Siberian Department of the USSR Academy of Sciences (Tikhonov and Panarina, 1980). A boar with a chromosome abnormality was identified among these animals during a routine cytogenetic study. The boar, issued from hybrid parents, was heterozygous for Robertsonian translocation 16/17.

The phenotype and sexual behavior of the boar were normal. He was used to cover 12 sows, but no offspring were obtained. Practically no sperm were observed in the seminal fluid. The absence of normal sperm in seminal canal apertures was confirmed by histological analysis of seminal tissue. Blood samples were used to prepare prometaphase chromosomes using Ikeuchi's technique (Ikeuchi, 1984) and to obtain high-resolution differential staining. In addition to seminal cell analysis, light microscope preparations of synaptonemal complexes were studied. They were identified on nitric oxide-silver-stained light microscope preparations of 'thrown flat' nuclei (Dresser and Moses, 1979).

\footnotetext{
* Author to whom all correspondence should be addressed.
} 


\section{RESULTS AND DISCUSSION}

G- and C-banded karyotypes of the boar carrying the translocation are presented in figures 1 and 2. Analyzing the chromosomes of this boar, one can see an

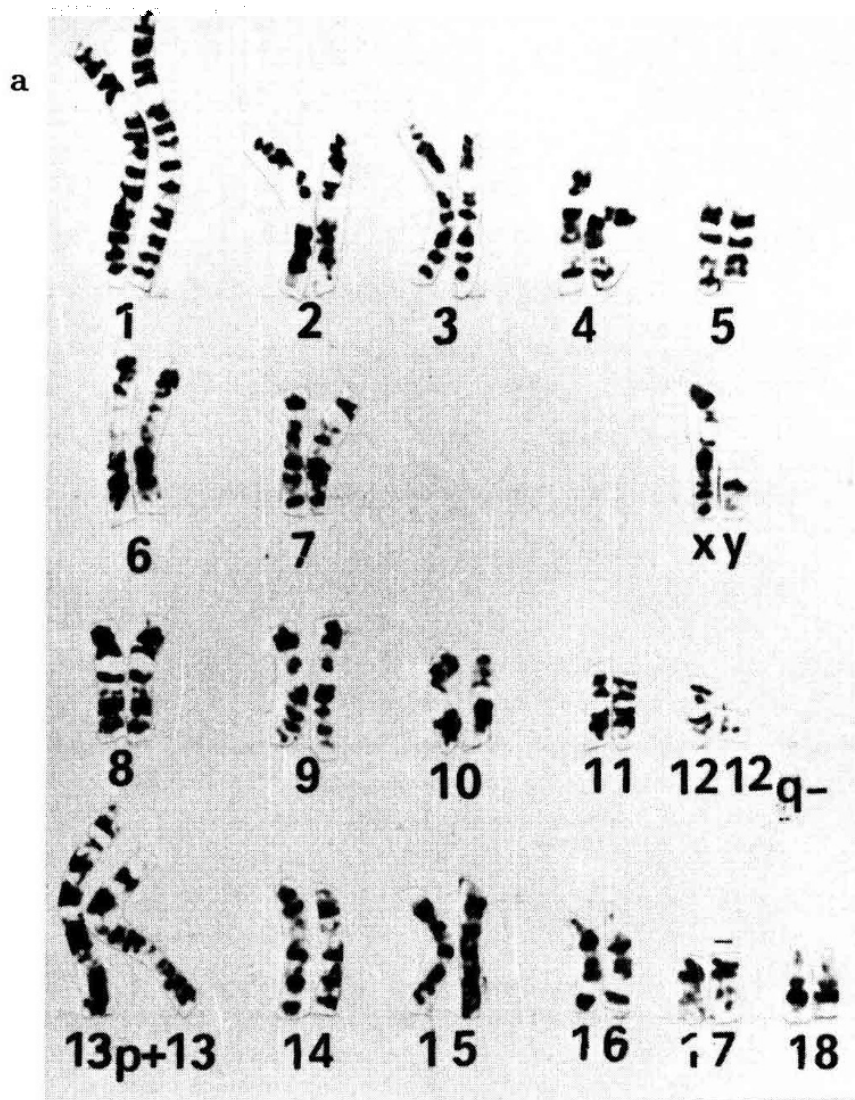

b

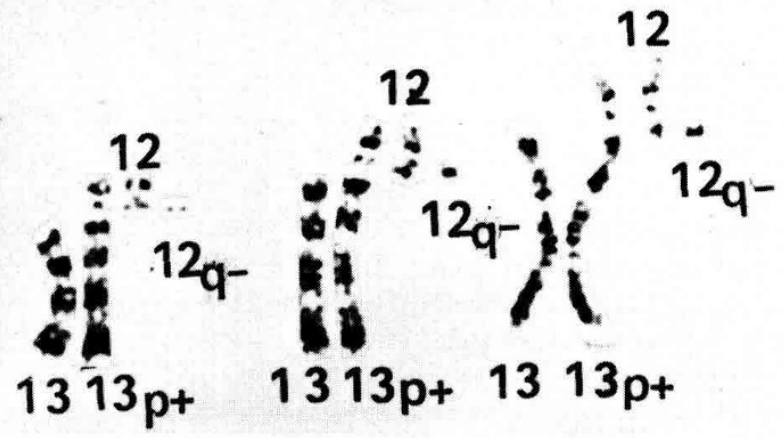

Fig 1. a. G-banded karyotype of the boar-carrier of the $12 / 13$ translocation. b. G-banded chromosomes of pairs 12 and 13 with different levels of resolution. 
additional arm on the largest acrocentric no 13 and a small element. Our analysis revealed that the $p$ and, apparently, a small part of the $q$ arm of one of the no 12 chromosomes had been translocated to one of the no 13 chromosomes. Figure $1 \mathrm{~b}$ shows chromosomes 12 and 13 from three cells at different stages of condensation; only high-resolution banding patterns enable analysis of the identified aberration in detail. The conservation of the centromere region of the chromosome 12 that participates in the aberration was confirmed by C-banding of chromosomes (fig 2).

Usually there is a great quantity of sperm in the seminal cell preparations. Having analyzed about 200 preparations from the animal under study, we identified no more than 10 mature spermatozoa. Normal animals have many cells at the diakinesis stage. The boar carrying the translocation had only four degraded diakinetic sperm and many pachytene cells. Figure 3 shows synaptonemal complexes; the chromosome 12 and 13 quadrivalent is characteristic of reciprocal translocation (Switonski and Gustavsson, 1986).

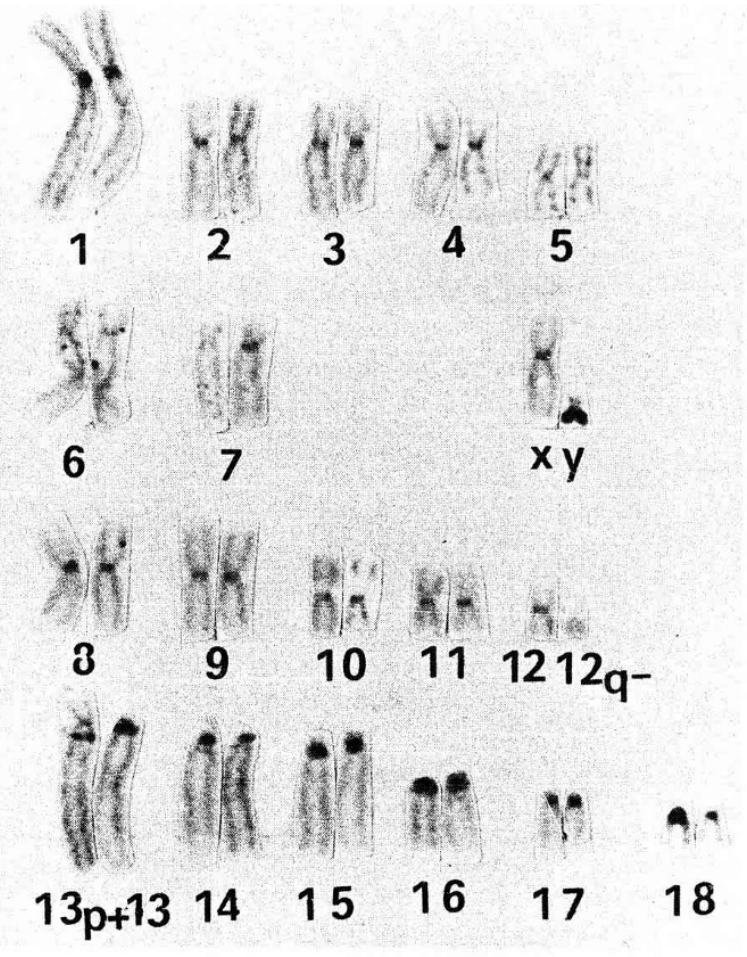

Fig 2. C-banded karyotype of the boar-carrier of the $12 / 13$ translocation.

Today, the data concerning chromosome aberrations in domestic pigs are numerous enough, and most of these aberrations are non-Robertsonian translocations (Gustavsson et al, 1982; Popescu et al, 1984). Aberrations were mostly identified in animals with normal phenotype and normal sexual behavior, but whose number of live offspring was reduced $25-100 \%$ as a result of unbalanced gametes. Only two 
a

b

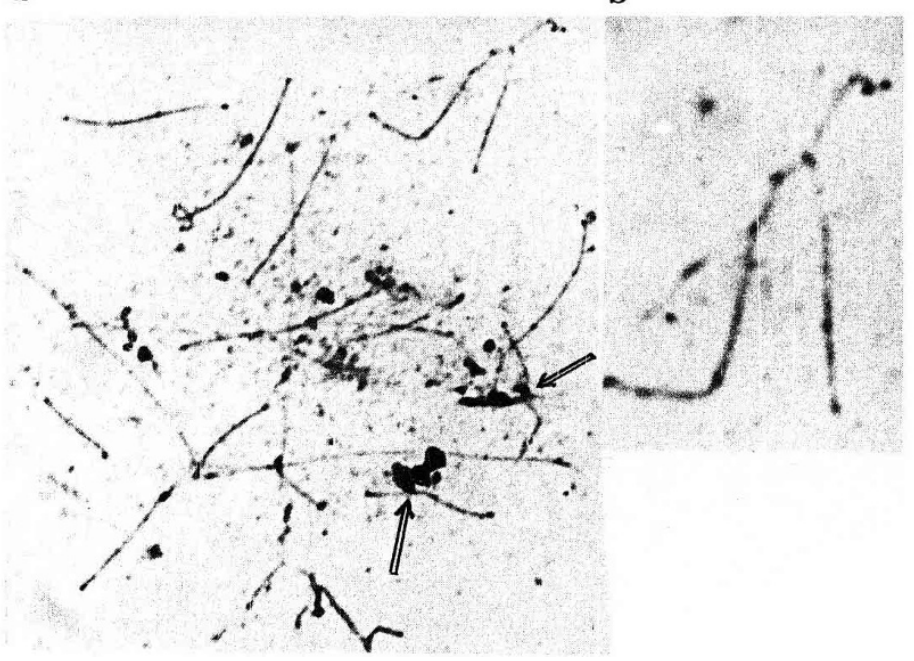

Fig 3. Synaptonemal complex of the pachytene stage. a. Bivalents formed by 8 and 10 nucleolar organizer region (NOR)-carrier chromosomes are shown (arrows) b. Quadrivalent formed by the rearranged and normal chromosomes of pairs 12 and 13.

of the translocation-carrier boars were absolutely sterile: $\mathrm{rcp} 6 \mathrm{p}+/ 15 \mathrm{q}-$ (Bouters et al, 1974) and $\mathrm{rcp} 12 \mathrm{q}-/ 13 \mathrm{p}+$. In the latter case, the number of diakinetic cells and sperm was essentially reduced. It is possible that some genotype component important for normal meiosis was affected by the aberration of chromosomes 12 and 13.

\section{REFERENCES}

Bouters R, Boute P, Spincemaille J, Vandeplassche M (1974) The chromosomes of domestic animals. Chromosomal abnormalities associated with reproductive disorders. Vlaams Diergeneeskd Tijdschr 43, 85-99

Dresser ME, Moses MJ (1979) Silver staining of synaptonemal complexes in surface spreads for light and electron microscopy. Exp Cell Res 121, 416-419

Fechheimer NS (1979) Cytogenetics in animal production. J Dairy Sci 62, 844-853

Gustavsson I (1980) Chromosome aberrations and their influence on the reproduction performance of domestic animals - a review. Z Tierz Zuechtungsbiol 97, 176-195

Gustavsson I, Settergren I, King WA (1982) Identification of three spontaneous reciprocal translocations in the domestic pig. Proc 5th Eur Colloq Cytogenet Domest Anim Milano, (Succi G, ed) 281-287

Ikeuchi $T$ (1984) Inhibitory effect of ethidium bromide on mitotic chromosome condensation and its application to high-resolution chromosome banding. Cytogenet Cell Genet 38, 56-61

Popescu CP, Tixier M (1984) The frequency of chromosomal abnormalities in domestic animals and their economic consequences. Ann Genet 27, 69-72

Popescu CP, Bonneau M, Tixier M, Bahri J (1984) Reciprocal translocations in pig. Their detection and consequences in animal performance and economic losses. $J$ Hered 75, 448452 
Switonski M, Gustavsson I (1986) Multivalent configuration at the pachytene stage of meiosis in animals carrying reciprocal or Robertsonian translocations. 7th European Colloquium on Cytogenetics of Domestic Animals, Warsaw, Poland. abstr 39-40

Tikhonov VN, Panarina LM (1980) Selection of laboratory minipigs through hybridization between European, Asian wild boar and domestic pigs. In: Hybridization of Ungulate Animals. 83-88 